Original Article

\title{
Effects of pulmonary rehabilitation education for caregivers on pulmonary function and pain in patients with lung cancer following lung resection
}

\author{
JONG-HWA JEONG ${ }^{1)}$, WON-GYU YOO ${ }^{2 *}$ \\ 1) Department of Physical Therapy, The Graduate School, Inje University, Republic of Korea \\ 2) Department of Physical Therapy, College of Biomedical Science and Engineering, Inje University: \\ 607 Obangdong, Gimhae, Gyeongsangnam-do 621-749, Republic of Korea
}

\begin{abstract}
Purpose] The purpose of this study was to evaluate the effects of a pulmonary rehabilitation education program for caregivers on patients who underwent lung resection surgery. [Subjects] Subjects who underwent lung resection by visual assisted thoracotomy (VATs) were selected and divided into a control group of 19 and an experimental group of 22. [Methods] The experimental group received a pulmonary rehabilitation education program for caregivers, while the control group received typical care for 4 weeks. This study assessed the subjects 2 weeks (baseline) and 6 weeks after surgery (4 weeks). The forced vital capacity (FVC) and forced expiratory volume in 1 sec (FEV1) were measured to evaluate pulmonary function. A visual analogue scale (VAS) was utilized to evaluate pain. [Results] Pulmonary function (FVC and FEV1) increased more in the experimental group compared with the control group. Furthermore, VAS scores were lower in the experimental group compared with the control group. [Conclusion] A pulmonary rehabilitation education program for caregivers had a positive effect on pulmonary function in patients with lung cancer after lung resection.

Key words: Caregiver, Lung resection, Pulmonary rehabilitation
\end{abstract}

(This article was submitted Aug. 1, 2014, and was accepted Sep. 2, 2014)

\section{INTRODUCTION}

Lung resection is an important treatment option for patients with lung cancer. However, many such patients, particularly those with severe chronic obstructive pulmonary disease, have a high risk of postoperative pulmonary complications ${ }^{1)}$. There is growing interest in the use of nonpharmacological interventions after lung resection or during cancer care, such as radiation therapy and chemotherapy. Pulmonary rehabilitation (PR) has been proposed to decrease the risk of postoperative pulmonary complications ${ }^{2)}$. It is necessary to develop a home-based exercise program to improve the function of patients and prevent postoperative pulmonary complications because the out-patient period is longer than the in-patient period. However, previous studies have focused mainly on PR for in-patients or only hospital workers, such as doctors, nurses, physical therapists, and respiratory therapists, provided the PR. Few studies on education programs for caregivers, which are the main supporters of home-based exercise programs during the outpatient period, have been conducted. The aim of this study was to

*Corresponding author. Won-gyu Yoo (E-mail: won7y@inje. ac.kr)

C2015 The Society of Physical Therapy Science. Published by IPEC Inc. This is an open-access article distributed under the terms of the Creative Commons Attribution Non-Commercial No Derivatives (by-ncnd) License $<$ http://creativecommons.org/licenses/by-nc-nd/3.0/>. evaluate the effects of a PR education program for caregivers on pulmonary function and pain in patients with lung cancer after lung resection.

\section{SUBJECTS AND METHODS}

The subjects comprised patients hospitalized within the Department of Thoracic Surgery of a National University Hospital between March and November 2013 who had not previously partaken in a pulmonary rehabilitation education program for caregivers and were scheduled for lung resection. This study was approved by the National University Hospital of Health Science Human Ethics Committee; all subjects provided written informed consent prior to participation. During the hospital stay for the surgery, all 50 subjects received the same general management (typical care) and were randomly divided into an experimental group $(\mathrm{n}=$ $25)$ and a control group $(n=25)$. Three subjects dropped out of the experimental group, and six dropped out of the control group during the 4-week study due to application of the exclusion criteria. Therefore, the study was completed with 22 subjects in the experimental group and 19 in the control group. Patients with other cardiopulmonary diseases, a congenital chest deformity, or rib fractures were excluded. After surgery, patients who received additional chemotherapy that weakened their body function were also excluded, as were those who did not attend the weekly PR education program. The assessments of subjects were performed by a physical therapist who was blinded to any information about the 
groups. The control group received the entire typical care program, including pain management, general education for postoperative care, incentive spirometer use training, mobilization of the upper limbs and trunk, and nebulizer use instructions from the Department of Thoracic Surgery. The experimental group partook in the PR education program for caregivers once per week for $30 \mathrm{~min}$, under the direction of a physical therapist instructor. The PR education program included instruction regarding splint cough, airway clearance techniques, diaphragm breathing, segmental breathing, exercises for upper and lower extremities, walking exercises, and stair exercises. The instructor demonstrated the procedures to caregivers, and then the caregivers practiced with their patients while the instructor observed. Pulmonary function was assessed by MicroLab (Micro Medical Ltd., Cambridge, UK). Forced vital capacity (FVC) and forced expiratory volume in $1 \mathrm{sec}$ (FEV1) were measured in accordance with the American Thoracic Society guidelines ${ }^{3}$. Pain after lung resection was evaluated using a visual analogue scale (VAS) ${ }^{4}$. Data were encoded and analyzed using SPSS for Windows ver. 12.0 (SPSS, Inc., Chicago, IL, USA). The statistical significance level was set at $\alpha=0.05$. The homogeneity of the general characteristics between the two groups was analyzed by $\chi^{2}$ test and independent t-test. The differences in the changes between the two groups before the experiment and at 2 weeks (baseline) and 6 weeks after surgery (4 weeks) were assessed by repeated-measures analysis of variance.

\section{RESULTS}

The average age, height, weight, and BMI of subjects were $60.22 \pm 10.89,163.01 \pm 8.77 \mathrm{~cm}, 61.39 \pm 11.35 \mathrm{~kg}$, and $23.01 \pm 3.34$, respectively. Pulmonary function (FVC and FEV1) in the experimental group increased significantly compared with that in the control group $(\mathrm{p}<0.01)$ (Table 1). VAS scores at 4 weeks and baseline differed significantly, but no differences were observed over time or among groups (Table 1).

\section{DISCUSSION}

Filaire et al. ${ }^{5)}$ reported that the FEV1/FVC ratio did not change, but the inspiratory and expiratory reserve volume decreased rapidly by $\sim 40 \%$ in the acute stage after lung resection in 31 patients with lung cancer (mean age, $59 \pm$ 10 years). Varela et al. ${ }^{6}$ showed that FEV1 decreased rapidly 1 day after surgery and then recovered slowly during the next 6 days, but it did not reach the previous level. Our results were similar, as the $\mathrm{FEV} 1 / \mathrm{FVC}$ ratio at baseline was 0.86 in the control group and 0.90 in the experimental group. However, the change in FVC differed before and after the experiment, as that in the experimental group increased by $21.1 \%$ compared with $5.8 \%$ in the control group. This was believed to be caused by the short study period (4 weeks)
Table 1. Comparison of pulmonary function and pain

\begin{tabular}{llcc}
\hline \multicolumn{2}{l}{ Mean $( \pm$ SD $)$} & Control & Experimental \\
\hline FVC & Baseline & $1.89( \pm 0.45)$ & $1.90( \pm 0.47)^{*}$ \\
& 4 weeks & $2.00( \pm 0.44)$ & $2.30( \pm 0.44)^{*}$ \\
\multirow{2}{*}{ FEV1 } & Baseline & $1.63( \pm 0.43)$ & $1.71( \pm 0.37)^{*}$ \\
& 4 weeks & $1.62( \pm 0.42)$ & $1.95( \pm 0.36)^{*}$ \\
\multirow{2}{*}{ VAS } & Baseline & $3.15( \pm 2.13)$ & $3.54( \pm 2.09)^{*}$ \\
& 4 weeks & $2.73( \pm 1.82)$ & $2.23( \pm 1.60)$ \\
\hline * $<<0.01$ & &
\end{tabular}

and the fact that each group received a different intervention. In contrast, a pilot study by Spruit et al. ${ }^{7)}$, applied an 8-week PR exercise program to inpatients who had undergone lung resection for lung cancer: all pulmonary functions, with the exception of FEV1, differed significantly, including functional exercise capacity. It would appear that the PR education program for caregivers, designed to improve pulmonary function (FVC and FEV1), was responsible for these differences: the previous study had focused on strengthening and aerobic exercises, such as walking. The pulmonary rehabilitation education program for caregivers had a positive effect on pulmonary function in patients with lung cancer following lung resection. In a previous study, the pain score (VAS) of patients who had undergone lung resection was 3.3 immediately after surgery, 2 at 2 weeks, and 1.5 at 6 weeks after surgery ${ }^{8}$. In our study, the VAS revealed significantly decreased pain in both groups, but no difference was observed between the two groups.

\section{REFERENCES}

1) Licker MJ, Widikker I, Robert J, et al.: Operative mortality and respiratory complications after lung resection for cancer: impact of chronic obstructive pulmonary disease and time trends. Ann Thorac Surg, 2006, 81: 1830-1837. [Medline] [CrossRef]

2) Shannon VR: Role of pulmonary rehabilitation in the management of patients with lung cancer. Curr Opin Pulm Med, 2010, 16: 334-339. [Medline] [CrossRef]

3) American Thoracic Society: Standardization of Spirometry, 1994 Update. Am J Respir Crit Care Med, 1995, 152: 1107-1136. [Medline] [CrossRef]

4) Yang HS, Yoo WG: The effects of stretching with lumbar traction on VAS and oswestry scales of patients with lumbar 4-5 herniated intervertebral disc. J Phys Ther Sci, 2014, 26: 1049-1050. [Medline] [CrossRef]

5) Filaire M, Bailly $P$, Chadeyras JB, et al.: [Evolution of the early respiratory function after lung resection for cancer]. Rev Pneumol Clin, 2009, 65: 85-92. [Medline] [CrossRef]

6) Varela G, Novoa NM, Agostini P, et al.: Chest physiotherapy in lung resection patients: state of the art. Semin Thorac Cardiovasc Surg, 2011, 23: 297-306. [Medline] [CrossRef]

7) Spruit MA, Janssen PP, Willemsen SC, et al.: Exercise capacity before and after an 8-week multidisciplinary inpatient rehabilitation program in lung cancer patients: a pilot study. Lung Cancer, 2006, 52: 257-260. [Medline] [CrossRef]

8) Nosotti M, Baisi A, Mendogni P, et al.: Muscle sparing versus posterolateral thoracotomy for pulmonary lobectomy: randomised controlled trial. Interact Cardiovasc Thorac Surg, 2010, 11: 415-419. [Medline] [CrossRef] 